\title{
Arbuscular mycorrhizal fungal phylogeny-related interactions with a non-host
}

\author{
Wagg, Cameron ; Antunes, Pedro Madeira ; Peterson, R Larry
}

\begin{abstract}
Arbuscular mycorrhizal fungi (AMF) form symbiotic relationships with most vascular plants including some gymnosperm species. Although species in the gymnosperm family Pinaceae normally develop ectomycorrhizal associations, AMF hyphae and vesicles, typical of members of the Suborder Glomineae, have been reported in the roots of some Pinaceae species. However, it is not known whether AMF belonging to various species and suborders are able to colonize roots of Pinaceae species and to what extent this influences the performance of Pinaceae seedlings. We tested in each of the Glomaceae, Acaulosporaceae and Gigasporineae AMF families two species for their ability to colonize and affect the growth of Pinus strobus (eastern white pine) in the presence or absence of an AMF host plant (Trifolium pretense-red clover). Glomus intraradices was the only AMF that colonized pine roots, predominantly in the presence of clover, forming intracellular hyphae and vesicles but not arbuscules. Colonization, however, did not relate to increased pine biomass and the overall presence of AMF, regardless of colonization abilities, resulted in a biomass reduction. This effect on pine seedling biomass was explained by the AMF family to which the AMF belonged, indicating that the effects of AMF on the non-host pine may be related to phylogeny. Acaulosporaceae species reduced pine biomass the most whereas, Gigasporineae species had the smallest effect on biomass. These preliminary results suggest that AMF may affect the soil microflora differently among AMF families in previously unsuspected ways with potential consequences for non-AMF host growth
\end{abstract}

DOI: https://doi.org/10.1007/s13199-011-0107-5

Posted at the Zurich Open Repository and Archive, University of Zurich

ZORA URL: https://doi.org/10.5167/uzh-155687

Journal Article

Published Version

Originally published at:

Wagg, Cameron; Antunes, Pedro Madeira; Peterson, R Larry (2011). Arbuscular mycorrhizal fungal phylogeny-related interactions with a non-host. Symbiosis, 53(1):41-46.

DOI: https://doi.org/10.1007/s13199-011-0107-5 


\title{
Arbuscular mycorrhizal fungal phylogeny-related interactions with a non-host
}

\author{
Cameron Wagg • Pedro Madeira Antunes • \\ R. Larry Peterson
}

Received: 17 November 2010 / Accepted: 10 February 2011 /Published online: 3 March 2011

(C) Springer Science+Business Media B.V. 2011

\begin{abstract}
Arbuscular mycorrhizal fungi (AMF) form symbiotic relationships with most vascular plants including some gymnosperm species. Although species in the gymnosperm family Pinaceae normally develop ectomycorrhizal associations, AMF hyphae and vesicles, typical of members of the Suborder Glomineae, have been reported in the roots of some Pinaceae species. However, it is not known whether AMF belonging to various species and suborders are able to colonize roots of Pinaceae species and to what extent this influences the performance of Pinaceae seedlings. We tested in each of the Glomaceae, Acaulosporaceae and Gigasporineae AMF families two species for their ability to colonize and affect the growth of Pinus strobus (eastern white pine) in the presence or absence of an AMF host plant (Trifolium pretense-red clover). Glomus intraradices was
\end{abstract}

C. Wagg

Ecological Farming Systems,

Agroscope Reckenholz Tänikon Research Station ART,

Reckenholzstrasse 191,

CH-8046 Zürich, Switzerland

C. Wagg $(\bowtie)$

Institute of Evolutionary Biology and Environmental Studies,

University of Zürich,

Winterthurestrasse 190,

CH-8057 Zürich, Switzerland

e-mail: cameron.wagg@art.admin.ch

P. M. Antunes

Department of Biology, Algoma University,

1520 Queen Street East,

Sault Ste. Marie, Ontario P6A 2G4, Canada

R. L. Peterson

Department of Molecular and Cellular Biology,

University of Guelph,

Guelph, Ontario N1G 2W1, Canada the only AMF that colonized pine roots, predominantly in the presence of clover, forming intracellular hyphae and vesicles but not arbuscules. Colonization, however, did not relate to increased pine biomass and the overall presence of AMF, regardless of colonization abilities, resulted in a biomass reduction. This effect on pine seedling biomass was explained by the AMF family to which the AMF belonged, indicating that the effects of AMF on the non-host pine may be related to phylogeny. Acaulosporaceae species reduced pine biomass the most whereas, Gigasporineae species had the smallest effect on biomass. These preliminary results suggest that AMF may affect the soil microflora differently among AMF families in previously unsuspected ways with potential consequences for non-AMF host growth.

Keywords Arbuscular mycorrhiza - Gigasporineae ·

Glomineae $\cdot$ Glomus intraradices $\cdot$ Non-host $\cdot$ Plant growth

\section{Introduction}

Arbuscular mycorrhizal fungi (AMF) colonize a wide diversity of vascular plants and are known to play an important role in many ecosystems influencing plant community composition and productivity (Smith and Read 2008). Members of the gymnosperm family Pinaceae, are generally considered to form associations with ectomycorrhizal fungi (EMF) only (Smith and Read 2008) and these have been demonstrated to improve seedling establishment and growth (Simard and Durall 2004). However, the presence of hyphae and vesicles, typical of AMF, have been observed in the roots of various members of the Pinaceae in field collected material (Cázares and Trappe 1993; Horton et al. 1998) and in plants grown in soil collected from forest sites (Cázares and Smith 1996; 
Wagg et al. 2008). These intracellular fungal structures are morphologically similar to AMF belonging to the Glomus genus. More recent reports have confirmed that Glomus intraradices will colonize roots of several Pinaceae species in the presence of an AMF companion plant (Smith et al. 1998; Wagg et al. 2008). However, it is not known whether other AMF are able to colonize non-AMF hosts either alone or in the presence of an AMF companion plant. The functioning of AMF in association with host plants has been shown to be related to phylogeny (Maherali and Klironomos 2007), yet whether phylogeny relatedness of AMF has any functional consequence on non-AMF host species is unknown. This is important for understanding how AMF communities interact with non-AMF host plants and the potential mechanisms by which AMF influence the growth of non-AMF host plants, such as some agricultural weeds (Rinaudo et al. 2010).

Angiosperm tree genera including Populus, Salix, and Eucalyptus can be colonized by both AMF and EMF within the same root system (Chilvers et al. 1987; Bellei et al. 1992; Lodge and Wentworth 1990; van der Heijden 2001). Typically, AMF are dominant during the early stages of seedling development (e.g. Chilvers et al. 1987; Bellei et al. 1992) and may be important for nutrient acquisition and growth during the first few months of seedling establishment prior to the development and functioning of EMF associations (Lodge and Wentworth 1990; van der Heijden 2001). Whether this might be the case with some members of the Pinaceae is not known.

We hypothesized that AMF belonging to different phylogenetic groups would differ in their colonization potential with a non-host plant species when inoculated alone or in the presence of an AMF host. To test this hypothesis we determined the potential of six different AMF to colonize and influence the growth of Pinus strobus L. (eastern white pine), considered to be a non-AMF host, either in the presence or absence of Trifolium pratense L. (common red clover), a well known AMF host. Of the AMF species tested, two belong to the Gigasporaceae family, Suborder Gigasporineae, a group which does not form intracellular vesicles, and two were from each of the Glomaceae and Acaulosporaceae families, of the Suborder Glomineae, which commonly form vesicles within host roots. We also assessed the extent to which the presence of AMF in the presence or absence of clover affects the biomass of pine seedlings and finally we discuss potential mechanisms and future directions.

\section{Materials and methods}

Seven AMF inocula treatments were used: Glomus intraradices Schenck \& Smith (INVAM accession code: IC101),
Glomus mosseae (Nicol. \& Gerd.) Gerd. \& Trapppe (MR104), (both in the Suborder Glomineae, Family Glomaceae); Entrophospora columbiana Spain \& Schenck (GA101), Acaulospora morrowiae Spain \& Schenck (CR207), (Suborder Glomineae, Family Acaulosporaceae); Gigaspora margarita Becker \& Hall (CU114), Scutellospora calospora (Nicol. \& Gerd.) Walker \& Sanders (AU222) (Suborder Gigasporineae, Family Gigasporaceae), and a mixture of all six AMF which was autoclaved $\left(121^{\circ}\right.$ C, $20 \mathrm{~min}$ ) and used as a control.

All AMF inocula were obtained from the International Culture Collection of (Vesicular) Mycorrhizal Fungi (INVAM, accession codes can be consulted at http:// invam.caf.wvu.edu/index.html). Inoculum of each isolate was bulked for experiments by mixing the starting material with sterile turface (calcined montmorillonite clay, Applied Industrial Materials, Buffalo Grove, IL, USA) : sand (1:1 vol/vol), seeding with Sudan grass (Sorghum vulgare var. sudanense), and maintaining the pot cultures for approximately 1 year in the University of Guelph phytotron under $25^{\circ} \mathrm{C}, 16 \mathrm{~h}$ days and $17^{\circ} \mathrm{C}, 8 \mathrm{~h}$ nights. Daylight was maintained at $200 \mu \mathrm{mol} \cdot \mathrm{m}^{-2}$ photosynthetically active radiation by an array of $400-\mathrm{W}$ high pressure sodium lights. Following this, water was withheld resulting in desiccation of plants and soil. Dried roots were then cut into manageable pieces, mixed with their original substrate, and stored in sealed plastic bags at $4^{\circ} \mathrm{C}$ until use. Inocula were carefully examined to verify that spores were abundant, appeared healthy, and that no spores of non-target species were present (see also Antunes et al. 2010).

Cone-tainers (Stuewe and Sons, Inc., USA) with $200 \mathrm{~mL}$ of rooting space were filled with $25 \mathrm{~mL}$ Sunshine Mix No. 2 (Sun Gro Horticulture Canada Ltd) pressed to cover the bottom holes followed by $100 \mathrm{~mL}$ of a 1: 1: 1 mixture of sand: Turface: soil, a layer of approximately $50 \mathrm{~mL}$ of inoculum, and another $25 \mathrm{~mL}$ of the sand: Turface: soil mixture. In total, we used 20 replicate cone-tainers for each of the six AMF inocula and 30 for the sterile control treatment. The sand: Turface: soil mixture and small volume of rooting space was used to enhance the contact between AMF and plant roots as well as to determine the effects that AMF activity may have on pine due to limited soil resources.

The soil used in the AMF culture pots and during the experiment was collected from the Long-Term Mycorrhiza Research Site (LTMRS) at the University of Guelph (Klironomos 2002). All substrate mixtures used in the experiment were autoclaved twice $\left(121^{\circ} \mathrm{C}, 20 \mathrm{~min}\right)$ to ensure sterility. Soil collected from the LTMRS was analysed after sterilization and contained $2 \pm 0.3 \mathrm{mg} \mathrm{NO}-\mathrm{N} \mathrm{kg}^{-1}, 10 \pm$ $1.0 \mathrm{mg} \mathrm{NH} \mathrm{NH} \mathrm{kg}_{4}-1,10 \pm 0.6 \mathrm{mg} \mathrm{NaHCO}$-extractable $\mathrm{P}$ $\mathrm{kg}^{-1}, 275 \pm 24 \mathrm{mg} \mathrm{CH} \mathrm{COONH}_{4}$-extractable $\mathrm{K} \mathrm{kg}^{-1}, 379 \pm$ $11 \mathrm{CH}_{3} \mathrm{COONH}_{4}$-extractable $\mathrm{Mg} \mathrm{kg}^{-1}$ and $7.3 \mathrm{pH}(1: 1$ in water; $n=3$, mean $\pm \mathrm{SE}$ ). 
Pinus strobus L. seeds obtained from the National Tree Seed Centre (Seed lot \# 20061139, Natural Resources Canada, Fredericton, New Brunswick, Canada) were surface sterilized by agitation in 5\% household bleach for approximately $5 \mathrm{~min}$, rinsed under running water and dried on filter paper overnight in a laminar flowhood. Each individual seed was massed to the nearest thousandth of a gram and weighed seeds were placed in rows in moist sterile sand in $15.5 \mathrm{~cm}$ diameter Petri dishes which were sealed to keep humidity high until germination approximately 25 days later. A single germinated pine seed with developed radicle was transferred into each cone-tainer at approximately $0.5 \mathrm{~cm}$ depth, and each cone-tainer was watered to capacity. Clover seeds, sterilized by agitation in a $15 \%$ solution of $\mathrm{H}_{2} \mathrm{O}_{2}$, were planted in ten of the 20 replicate pots of each inoculum treatment at the same time as pine. To correct for differences in non-AM microbial communities, each experimental unit received $1 \mathrm{~mL}$ of $20 \mu \mathrm{m}$ filtered washing comprised of a mixture of each inoculum (Ames et al. 1987; Koide and Li 1989). The containers were arranged on the greenhouse bench in a completely randomized manner and seedlings were allowed to grow for 7 weeks under the conditions described for the inoculum cultures above.

At harvest, pine seedlings were rinsed to remove attached soil, excised at the shoot collar, and the fresh mass of all roots was recorded. Shoots were dried at $60^{\circ} \mathrm{C}$ for a minimum of 7 days after which the dry biomass was recorded. Of the non-mycorrhizal pine control seedlings, five root systems grown in absence of clover and five grown with clover were also dried and weighed. This was done to estimate the dry biomass from the fresh biomass using a linear regression equation $\left(\mathrm{R}^{2}=0.92\right)$ for seedlings whose roots were used for assessing AMF colonization.

We determined AMF colonization of the clover roots by clearing in $10 \% \mathrm{KOH}$ for $30 \mathrm{~min}$, staining in $5 \%$ pen ink in $5 \%$ acetic acid for 20 min (described in Vierheilig et al. 1998), mounting on microscope slides with $50 \%$ glycerine and scoring qualitatively at $100 \times$ magnification using a Leitz Orthoplan light microscope (Leica, Mississauga, Ontario). To assess pine root colonization, roots were cut into approximately $1 \mathrm{~cm}$ lengths. Half of these were cleared in $10 \% \mathrm{KOH}$ for $2 \mathrm{~h}$, bleached in $5 \%$ household bleach, and stained in $0.05 \%(w / v)$ trypan blue in lactoglycerol (Brundrett et al. 1994) for $1 \mathrm{~h}$ instead of ink-vinegar to ensure a better staining of any fungal endophytes present. These root segments were mounted on microscope slides with $50 \%$ glycerine and scored at $250 \times$ magnification with a Leitz Orthoplan light microscope for the presence of colonization by AMF structures. The number of vesicles per colonized $\mathrm{cm}$ of root was also determined.

ANOVA was used to assess pine seedling biomass (shoot + root biomass) using the presence of clover and its interaction with AMF family and AMF species within family as sources of variation. Differences in mean total dry weight of pine among AMF inocula treatments were determined by the Tukey's HSD test. Twelve pine seedlings did not survive transplanting and were removed from the data (6 E. columbiana, $2 G$. mosseae, 2 Gi. margarita, $1 \mathrm{G}$. intraradices and $1 \mathrm{~S}$. calospora). To determine whether AMF colonization and the formation of vesicles by $G$. intraradices influenced pine seedling biomass, we used a regression model with overall \% root length colonized and number of vesicles per $\mathrm{cm}$ of colonized root as predictors of pine biomass. Initial seed weight was added to all statistical models as a covariate. All statistical analyses were computed using R 2.10.1 (The R foundation 2004-2009).

\section{Results}

All clover and pine seedlings grown in the sterilized control treatment were free of any AMF or non-AMF structures. In contrast, clover roots were colonized by AMF forming intracellular hyphae, arbuscules and, depending on the species, vesicles in all mycorrhizal treatments (see Fig. 1a as an example). Pine seedlings were colonized by intraradical hyphae of $G$. intraradices, which formed numerous vesicles (Fig. 1b); arbuscules were absent in all roots examined. In the presence of clover, eight of nine pine seedlings were colonized by $G$. intraradices. In the presence of clover, $G$. intraradices colonized $40.0 \%$ ( $\mathrm{SE}=$ 10.1) of the root-length and formed $22.1(\mathrm{SE}=7.6)$ vesicles (Fig. 1b) per $\mathrm{cm}$ of colonized root. Conversely, in the absence of clover, only two of the ten pine seedlings became colonized by $G$. intraradices exhibiting $10.7 \%$ ( $\mathrm{SE}=$ 1.9) of root-length colonized and $4.5(\mathrm{SE}=0.3)$ vesicles formed per $\mathrm{cm}$ of colonized root. Both the \% root-length colonized and the number of vesicles per $\mathrm{cm}$ of colonized root formed by $G$. intraradices did not relate significantly to the biomass of pine seedlings $\left(\mathrm{F}_{1,15}=0.72, p=0.41\right.$ and $\mathrm{F}_{1,15}=$ $1.93, p=0.19$, respectively).

The total biomass of pine seedlings was significantly influenced by the presence of clover $\left(\mathrm{F}_{1,129}=19.8, p<\right.$ 0.0001). Overall, pine biomass was reduced in the presence of this AMF host (Fig. 2). The influence of AMF inocula on pine biomass was significantly explained at the AMF family level $\left(\mathrm{F}_{3,129}=8.34, p<0.0001\right)$ leaving no significant portion of variation to be explained by differences among AMF species $\left(\mathrm{F}_{3,129}=0.80, p=0.50\right)$. An interaction between AMF inocula and the presence of clover was not detected indicating the effect of clover on pine did not depend on AMF treatment or family. Thus, the interaction terms were omitted from the ANOVA model. The biomass of pine was significantly depressed 

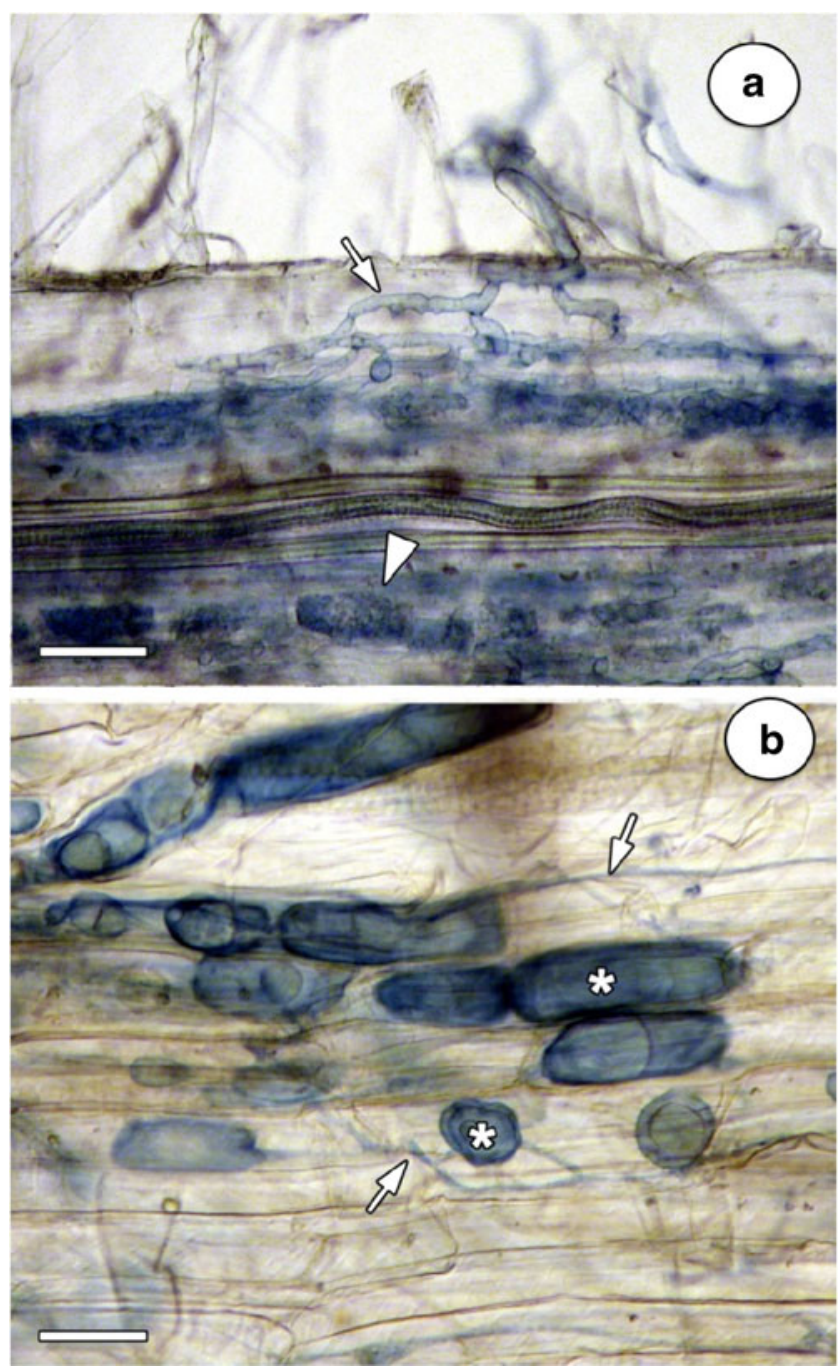

Fig. 1 Colonization by arbuscular mycorrhiza: a colonization of T. pratense by Gigaspora margarita forming intraradical hyphae (arrow) and arbuscules (arrowhead); b colonization of Pinus strobus by intraradical hyphae (arrows) and vesicles $\left(^{*}\right)$ of Glomus intraradices. Scale bars $=50 \mu \mathrm{m}$

below that of the control treatment by inoculation with Glomineae (Glomaceae $p=0.006$ and Acaulosporaceae $p<$ 0.0001 ) while Gigasporineae inocula resulted in no significant reduction (Fig. 2). Aculosporaceae species resulted in the greatest reduction in pine biomass which differed significantly from the Gigasporineae species that had the least negative influence on pine biomass (Fig. 2).

\section{Discussion}

Of the six AM fungal species tested, only $G$. intraradices colonized the non-AMF host $P$. strobus. Colonization occurred more consistently when clover was present likely due to the production of root exudates, such as strigolac-

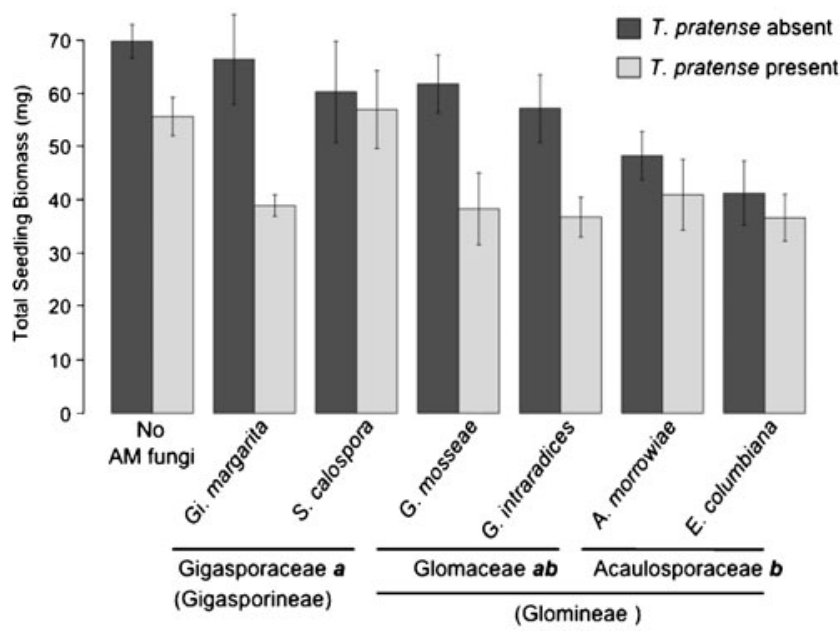

Fig. 2 Mean and standard errors of the mean of the total P. strobus seedling biomass for each of the AMF inoculum treatments in the presence or absence of clover. Mean $P$. strobus biomass differed significantly $(p<0.05)$ from the control treatment (no AMF) when inoculated with both Glomaceae and Aculosporaceae fungi, but not when inoculated with Gigasporaceae fungi. Significant differences among AMF families in their effect on $P$. strobus biomass are indicated by different letters following family names (Tukey HSD $p<0.05$ )

tones, that can stimulate AMF hyphal proliferation (Giovannetti et al. 1993). This agrees with previous findings (Cázares and Trappe 1993; Horton et al. 1998; Smith et al. 1998; Wagg et al. 2008) and indicates that this AMF may be unique in its ability to colonize atypical hosts. Although $G$. intraradices structures within pine roots did not relate to increased pine biomass, it was not determined whether the intraradical hyphae and vesicles of G. intraradices developed a host-derived perifungal membrane, an essential feature of an endophytic mycorrhizal fungus (Genre and Bonfante 2005). It is possible that fungal structures formed within dead cells, however, further microscopy is needed to determine the interactions between $G$. intraradices and pine root cells.

The production of large numbers of vesicles by $G$. intraradices in pine may be a strategy for persistence of this fungal species contributing to its widespread distribution in diverse ecosystems including boreal Scots pine (Pinus sylvestris L.) forests (Öpik et al. 2003, 2006). This suggestion is supported by the fact that vesicles act as storage structures (Bonfante-Fasolo 1986) and as viable propagules (Biermann and Linderman 1983) even after long periods of storage (Plenchette and Strullu 2003). Although only $G$. intraradices colonized pine roots, this AMF species as well as all those tested (particularly two species of Glomineae fungi), resulted in reduced pine seedling biomass.

The overall reduction in pine biomass in all inoculated treatments in the presence of clover compared to the 
control was likely due to the colonized clover roots having a competitive advantage over pine roots in acquiring limited nutrients from the soil. Similar growth depressions in plants resulting from AMF-mediated plant-plant competition are known to occur (Hartnett et al. 1993; Rinaudo et al. 2010).

Although not as pronounced, there was also a general reduction in pine seedling biomass in the absence of clover in AMF inoculated treatments. This difference in reduction in pine biomass among AMF species was explained at the family level. Family-wise differences in AMF plant and soil colonization as well as the provision of $\mathrm{P}$ to host plants has previously been observed (Maherali and Klironomos 2007). However, until now, differences among AMF families in their effects on non-host plants had not been reported. The Acaulosporaceae species, which did not colonize pine in any case, resulted in somewhat similar growth reductions in both the presence and absence of clover, demonstrating that a mechanism other than plant-plant competition negatively influenced pine seedling biomass production. It is possible that in the absence of clover the developing AMF mycelium derived from germinating spores and colonized root pieces in the inoculum may have been effective in competing with pine for soil resources. However, this is perhaps unlikely since AMF are known to be obligate symbionts (Smith and Read 2008). Alternatively, the microbial wash may not have established similar non-AMF soil microbial communities among treatments and, as a result, the AMF-associated microbes present in the inocula could have been responsible for the pine growth reduction in the absence of clover. For example, specific bacterial communities are known to associate with the hyphal surface of AMF and these bacterial communities in the hyphosphere differ among AMF species (Bharadwaj et al. 2008; Scheublin et al. 2010). This could explain the AMF family-wise effects we observed in the absence of clover and suggests that hyphosphere bacterial communities may be a key factor affecting the growth of pine seedlings in our study; perhaps indicating additional roles by which AMF phylogeny could influence interactions among soil organisms. Competition between soil microbes and plants is known to occur (Harrison et al. 2007; Kaye and Hart 1997) and the competition for soil nitrogen (Dunn et al. 2006) may have resulted in the reduced biomass of pine seedlings. The ability of hyphosphere bacterial communities to associate with specific AMF families and compete with non-host plants for soil resources has yet to be explored. This would provide novel insights into potential mechanisms behind negative AMF-associated growth responses regardless of the colonization abilities of AMF and should be explored further.
Acknowledgements Funding was provided by a Natural Sciences and Engineering Research Council of Canada Discovery grant to RLP. We thank Shannon Seahra for her help in processing the roots for microscopy and Rita Veiga for insights into discussion points. We are grateful for comments by the two anonymous reviewers which helped improve the manuscript.

\section{References}

Ames RN, Mihara KL, Bethlenfalvay GJ (1987) The establishment of microorganisms in vesicular-arbuscular mycorrhizal and control treatments. Biol Fert Soils 3:217-223

Antunes PM, Koch AM, Morton JB, Rillig MC, Klironomos JN (2010) Evidence for functional divergence in arbuscular mycorrhizal fungi from climatic origins. New Phytol. doi:10.1111/ j.1469-8137.2010.03480.x

Bellei MM, Garbaye J, Gil M (1992) Mycorrhizal succession in young Eucalyptus viminalis plantations in Santa Catarina (southern Brazil). For Ecol Manag 54:205-213

Bharadwaj DP, Lundquist P-O, Persson P, Alström S (2008) Evidence for specificity of cultivable bacteria associated with arbuscular mycorrhizal fungal spores. FEMS FEMS Micro Ecol 65:310-322

Biermann B, Linderman RG (1983) Use of vesicular-arbuscular mycorrhizal roots, intraradical vesicles and extraradical vesicles as inoculum. New Phytol 95:97-105

Bonfante-Fasolo P (1986) Anatomy and morphology of VA mycorrhiza. In: Powell CL, Bagyaraj D (eds) VA mycorrhizae. CRC Press Inc, Boco Raton, pp 5-33

Brundrett M, Melville L, Peterson L (1994) Practical methods in mycorrhiza research. Mycologue, Waterloo

Cázares E, Smith JE (1996) Occurrence of vesicular-arbuscular mycorrhizae in Pseudotsuga menziesii and Tsuga heterophylla seedlings grown in Oregon Coast Range soils. Mycorrhiza 6:65-67

Cázares E, Trappe JM (1993) Vesicular endophytes in roots of the Pinaceae. Mycorrhiza 2:153-156

Chilvers GA, Lapeyrie FF, Horan DP (1987) Ectomycorrhizal vs endomycorrhizal fungi within the same root system. New Phytol 107:441-448

Dunn R, Mikola J, Bol R, Bardgett RD (2006) Influence of microbial activity on plant-microbial competition for organic and inorganic nitrogen. Plant Soil 289:321-334

Genre A, Bonfante P (2005) Building a mycorrhizal cell: how to reach compatibility between plants and arbuscular mycorrhizal fungi. J Plant Interact 1:3-13

Giovannetti M, Avio L, Sbrana C, Citernesi AS (1993) Factors affecting appressorium development in the vesicular-arbuscular mycorrhizal fungus Glomus mosseae (Nicol. \& Gerd.) Gerd. \& Trappe. New Phytol 123:115-122

Harrison KA, Bol R, Bardgett RD (2007) Preferences for different nitrogen forms by coexisting plant species and soil microbes. Ecology 88:989-999

Hartnett DC, Hetrick BAD, Wilson GWT, Gibson DJ (1993) Mycorrhizal influence on intra and interspecific neighbor interactions among co-occurring prairie grasses. J Ecol 81:787-795

Horton TR, Cázares E, Bruns TD (1998) Ectomycorrhizal, vesiculararbuscular and dark septate fungal colonization of bishop pine (Pinus muricata) seedlings in the first 5 months of growth after wildfire. Mycorrhiza 8:11-18

Kaye JP, Hart C (1997) Competition for nitrogen between plants and soil microorganisms. Trends Ecol Evol 12:139-143

Klironomos JN (2002) Feedback with soil biota contributes to plant rarity and invasiveness in communities. Nature 417:6770 
Koide RT, Li M (1989) Appropriate controls for vesicular-arbuscular mycorrhiza research. New Phytol 111:35-44

Lodge DJ, Wentworth TR (1990) Negative association among VAmycorrhizal fungi and some ectomycorrhizal fungi occupying the same root system. Oikos 57:347-356

Maherali H, Klironomos JN (2007) Influence of phylogeny on fungal community assembly and ecosystem functioning. Science 316:1746-1748

Öpik M, Moora M, Liira J, Kõljalg U, Zobel M, Sen R (2003) Divergent arbuscular mycorrhizal fungal communities colonize roots of Pulsatilla spp. in boreal Scots pine forest and grassland soils. New Phytol 160:581-593

Öpik M, Moora M, Liira J, Zobel M (2006) Composition of rootcolonizing arbuscular mycorrhizal fungal communities in different ecosystems around the globe. J Ecol 94:778-790

Plenchette C, Strullu DG (2003) Long-term viability and infectivity of intraradical forms of Glomus intraradices vesicles encapsulated in alginate beads. Myc Res 107:614-616

Rinaudo V, Bàrberi P, Giovannetti M, van der Heijden MGA (2010) Mycorrhizal fungi suppress aggressive agricultural weeds. Plant Soil 333:7-20
Scheublin TR, Sanders IR, Keel C, van der Meer JR (2010) Characterisation of microbial communities colonizing the hyphal surfaces of arbuscular mycorrhizal fungi. ISME 4:752-763

Simard SW, Durall DM (2004) Mycorrhizal networks: a review of their extent, function, and importance. Can J Bot 82:1140-1165

Smith SE, Read DJ (2008) Mycorrhizal symbiosis, 3rd edn. Academic, London

Smith JE, Johnson KA, Cázares E (1998) Vesicular mycorrhizal colonization of seedlings of Pinaceae and Betulaceae after spore inoculation with Glomus intraradices. Mycorrhiza 7:279-285

Van der Heijden EW (2001) Differential benefits of arbuscular mycorrhizal and ectomycorrhizal infection of Salix repens. Mycorrhiza 10:185-193

Vierheilig H, Coughlan AP, Wyss U, Piché Y (1998) Ink and vinegar, a simple staining technique for arbuscular-mycorrhizal fungi. App Env Micro 64:5004-5007

Wagg C, Pautler M, Massicotte HB, Peterson RL (2008) The cooccurrence of ectomycorrhizal, arbuscular mycorrhizal, and dark septate fungi in seedlings of four members of the Pinaceae. Mycorrhiza 18:103-110 